\title{
Health-Improvement Competences Formation Technique in Future Police Officers by Means of Personality-Oriented Approach to Physical Education
}

\author{
Igor M. Kopotun* \\ Academia HUSPOL \\ Hranice, Czech Republic \\ Bohdan M. Holovkin \\ Department of Criminology and Criminal and Executive Law, \\ Yaroslav Mudryi National Law University \\ Kharkiv, Ukraine \\ Larysa R. Nalyvaiko \\ Dnipropetrovsk State University of Internal Affairs \\ Dnipro, Ukraine \\ Iryna O. Hrytsai \\ Dnipropetrovsk State University of Internal Affairs \\ Dnipro, Ukraine \\ Olena V. Tkachova \\ Department of Criminology and Criminal and Executive Law, \\ Yaroslav Mudryi National Law University \\ Kharkiv, Ukraine
}

\begin{abstract}
The objective of this study is to experimentally test how the technique based on a "21-day Health Marathon" training under the students' own program of intensive physical self-training being supervised by a personal tutor and stimulated by daily gain-and-lossframed messages, and elements of gamification (badges for certain achievements) influences the formation of health-improvement competencies for future police officers, their learning motivation, conscious learning and to what extend this technique reformats students' way of thinking in terms of continuous health-improvement. The 2X2 method of randomized split plots was used to analyze the quantitative data. A two-way ANOVA was used to identify the main
\end{abstract}

"Corresponding author e-mail: igorsazonetss@gmail.com 
results for the factors in the columns and lines, and to determine the degree of their interaction in the context of determining the effectiveness of the experiment. The data obtained in the focus group survey were processed using Textalyser web tool. To process students' answers to the questions, we identified the most commonly used positive words in the answers that helped us identify broad categories of answers such as: "improvement", "health", "motivation", "speed", "concentration", "future work". The research has shown that the use of this model has a positive impact on the state of development of value-motivational and activity-reflexive components of health-improvement competencies in future police officers, as well as on their awareness of the main direction and model of their future professional activity focused on the formation of personality traits, and not just on obtaining a certain volume of theoretical professional knowledge.

Keywords: high school; future police officers; health-improvement competences; physical education; personality-oriented approach.

\section{Introduction}

Employment in law enforcement agencies requires police officers to have a number of physical skills related to aerobic and muscular endurance, physical strength and agility (DeNysschen et al., 2018; Lagestad \& Van den Tillaar, 2014; Mahony \& Prenzler, 1996). Therefore, higher educational institutions that train police officers instil the need for individual physical fitness of students through the formation of health-improvement competencies, with emphasis being placed on the significant dependence of the efficiency of work, duration of career of the law enforcement officer, his/her work safety, their health condition and work capacity (Nabeel, Baker, McGrail \& Flottermesch, 2007). Benefits that future police officers gain from physical fitness include: increased resource of physical strength for dealing with emergency situations requiring the use of physical strength, improved general state, reduced risk of chronic diseases, and confident psychological well-being (Lagestad \& Van den Tillaar, 2014). Conversely, lack of physical fitness can be detrimental to officers' performance of their official duties and may lead to increased incidence of injuries, increased risk of cardiovascular disease, decreased productivity and, in the future, increase in healthcare costs for police departments across the country (Dimitrijevic et al., 2014; Dawes, Orr \& Cocke, 2016).

The study of academic sources on research problems has revealed that there is currently a limited number of research on the development of training and educational programs based on higher law enforcement education that would guide young people towards the development of healthy behaviours throughout life, such as regular physical load, stress management and dietary food (Plotnikoff et al., 2015; Simons-Morton, McLeroy \& Wendel, 2011). Therefore, the introduction of a comprehensive approach to the formation of healthimprovement competencies in future police officers at the higher educational institutions of law enforcement, which can provide lifelong health-improvement skills, is currently an urgent scientific pedagogical problem. 
With this in mind, we determined the objective of our study - to experimentally test the following:

1) how the developed health-improvement competencies formation technique in future police officers in means of a personality-oriented approach to physical education, which includes a "21-day Health Marathon", training under their own program of intensive physical selftraining under personal guidance of a tutor with a focus on gain-andloss-framed messages (Rothman, Bartels, Wlaschin \& Salovey, 2006), elements of gamification (badges for certain achievement) (Dicheva, Dichev, Agre \& Angelova, 2015; Greenberg, 2015; Marczewski, 2013; O'Donovan, Gain \& Marais, 2013), influences the formation habits that are components of health competencies for future police officers and their way of thinking, aimed at the formation of health-improvement competences, learning motivation, conscious learning;

2) how effective are those educational tools aimed at reformatting students' minds?

\section{Materials, Methods and Procedure of the Research}

The empirical experimental study used a set of general scientific theoretical, empirical and statistical methods, which were as follows: empirical, diagnostic, experimental and statistical methods. Theoretical empirical methods included analytical review of scientific achievements of the Ukrainian and foreign scholars on pedagogy and psychology applied to identify the scope of study, to analyse foreign best practice of integrated implementation of the elements of intensive pedagogy and personality-oriented approach through pedagogical mentoring. Furthermore, there was conducted the review of message framing theory (the impact of gain-and-loss-framed messages on behaviour), and gamification in curriculum followed by a theoretical substantiation of the development of methods to diagnose the effectiveness of this integrated technique in the system of physical education in professional training of police officers. Different further outlined diagnostic tools were used to collect experiments data. Those were the questionnaires for receiving feedback from students, a technique of studying the motivation of professional activity (Your psychologist, n./d.; Dobre, 2013), Murzina's (2014) technique for identifying the value orientations of personality "Square of Values", an orientation questionnaire "Personality Orientation" by Bass (Psychology of Happy Life, 2008); a technique of studying the level of formation of a design competence, modified diagnostic techniques of Semichenko (2004) "Motives for Studying in a Higher Educational Institution", the methods "Self-Assessment of Emotional State" by Wasmann and Ricks (Kokun, Pishko, Lozinska, Kopanytsia \& Malkhazov, 2011); the method and scale for determining the adaptation potential (Baiev, 2014), the method for determining biological age and computer rapid health diagnostics by Biopulsar-Reflexograph. Prior to the above, we designed the criteria and indicators to measure the impact of our model on the progress of future police officers in their overall physical fitness. The experiment was aimed to determine the degree of influence of the implementation of the model on the state of development of value-motivational and activity-reflexive components of student's activity in physical education. With regard to statistical 
methods, this study used quantitative and qualitative analysis of the results of experimental work, their graphical and analytical interpretation, establishment of statistical significance of the results of the study. Textalyser (n./d.) software was used to process the answers of the students of experimental group to the open questions of the questionnaire for the self-assessment.

The experiment consisted of two stages: 1) diagnostic and conceptual; 2) experimental. The first stage was implemented during the first half of 2019 and was aimed at determining the subject of training, namely, determining the list of health-improvement competencies required for future police officers and developing a model for the formation of health-improvement competencies in future police officers by a personality-oriented approach.

The experimental stage began immediately after obtaining permission for the study from the Academic Council and the Administration of the National Academy of Internal Affairs, Kyiv, and lasted during the second half of 2019. At this stage, a control and experimental group of students was formed, consisting of 27 and, accordingly, 29 students of the $11^{\text {st }} 4^{\text {th }}$ year of study, speciality 262 : Law Enforcement. The subject of Physical Education was taught to the students of the control group according to the traditional model, and the educational activities of the students of the experimental group were implemented through the use of blended learning techniques (Boucher et al., 2013; Findlay-Thompson \& Mombourquette, 2014) as part of "21-day Health Marathon". Such an organization of student learning included the development of their own program of intensive physical self-training under the personal guidance of a tutor, which was supported by daily gain-and-loss-framed messages and elements of gamification (badges for certain achievements).

The preparatory stage included the creation of daily gain-and-loss-framed messages developed. Gain-and-loss-framed messages were intended to catalyze changes in the model of behaviour of participants in the experiment and were divided into informative, motivational and instructive. They were previously posted at Google Calendar and launched with the start of the experiment.

Let us graphically present an experimental model of the formation of healthimprovement competencies in future police officers by means of a personalityoriented approach to physical education (see Figure 1). 


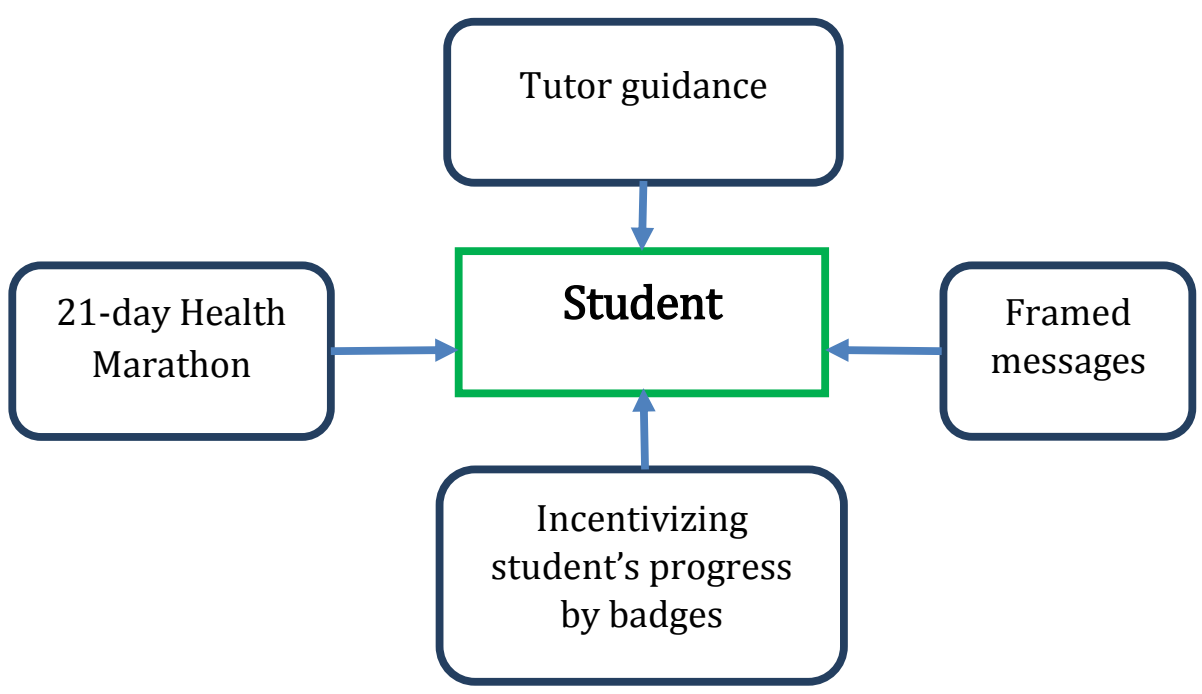

Figure 1: Experimental model of the formation of health-improvement competencies in future police officers by means of a personality-oriented approach to physical education

Implementation - development and executing own health-improvement program and determining its effectiveness by an expert committee and a student. Reflexive - summing up, carrying out repeated slices of the level of development of valuemotivational, activity-reflexive components of the activity of students of the control and experimental groups of physical education.

\subsection{Description of the course of the study}

As shown in the chart, the study was conducted in several stages: preparatory, implementation and reflexive (see Figure 2).

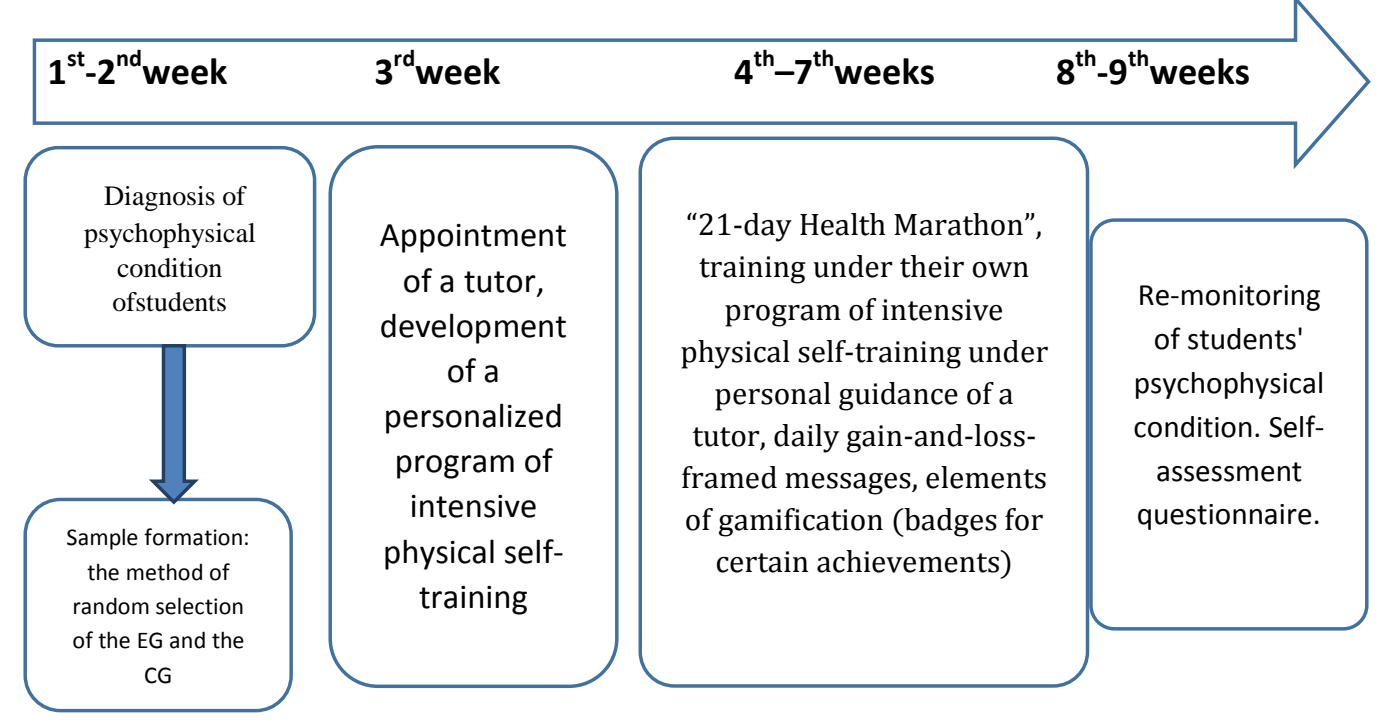

Figure 2: Chronology of the course of study

The objective of this research organization was to create an environment of intensive formation of habits that are an integral part of the health-improvement competencies of future police officers through a personality-oriented approach 
to physical education. We determined thinking styles aimed at the formation of health-improvement competencies, learning motivation, conscious learning as variables.

\subsection{Sample formation}

The objects of this study were students of the $1^{\text {st }} 4^{\text {th }}$ years of the speciality 262 : Law Enforcement of the National Academy of Internal Affairs, Kyiv. The total number of students involved in the empirical part of the experiment was 344 persons - a sample was formed using a random sampling method. The specified number of persons was further reduced by 138 persons due to the exclusion criterion, namely, health condition, and amounted to 206 persons. A sample size calculator (Google Apps) was used to determine the size of a representative sample to ensure the quality and reliability of the experiment results, given that $n$ (population size) $=206$, confidence interval $=2.34$, and $e=0.05$ if confidence level $=95 \%$. Therefore, the required sample size was to be 53 persons, and this number was used to form the experimental (EG) and control (CG) groups for this study. At this stage, a control and experimental group of students was formed, consisting of 28 (14 women aged 19-21 and 14 men aged 20-22) in the control group (CG)and, accordingly, 29 students (15 women aged 19-21 and 14 men aged 20-22) in the experimental group (EG).

A t-test based on the averages of the diagnostic tests listed above was conducted to determine if there were any statistically significant differences between these indicators in the two groups (see Table 1).

Table 1: T-test results based on the averages of the above listed diagnostic tests conducted in both groups

\begin{tabular}{|l|l|l|l|l|l|l|}
\hline Groups & $n$ & \multicolumn{5}{|c|}{ Estimated parameters } \\
\cline { 3 - 7 } & & $M$ & $S D$ & $S E$ & $t$-test & $p$ \\
\hline Control group & 28 & 3.5111 & 1.13824 & 55 & 0.71 & 0.458 \\
\hline Experimental group & 29 & 3.2356 & 1.11483 & & & \\
\hline
\end{tabular}

Note. $p<.05 ; n$ - number of students; $M$ - arithmetic mean; $S D$ - standard deviations; $S E$ standard error.

\subsection{Data collection instruments}

Several data collection tools were used in this study. Comprehensive monitoring of students' psychophysical condition using the above techniques and a selfassessment questionnaire were used to answer the first research question. On the other hand, a focus group survey was used to answer the second research question.

\subsection{Questionnaire for focus group survey}

In order to increase the validity of the survey results, a detailed review of the scientific literature on the relevant topic was conducted before the development of the questionnaire. The Textalyser (n./d.) application was used to analyze the answers. The focus group consisted of 11 students ( 5 men and 6 women). The questionnaire consisted of 6 questions: 
1) What proportion of time per week did you devote to participating in project-related activities?

2) How much time per week did you spend to implement the theoretical part of the project?

3) What exactly did you do in this project?

4) What benefits can you personally get from participating in this project?

5) What problems did you face while participating in the project?

6) What do you propose to do to solve the problems you faced?

\subsection{Data analysis}

The $2 \times 2$ method of randomized split plots was used to analyze the quantitative data. A two-way ANOVA (regression analysis involving two qualitative factors) was used to indicate the main results for the factors in the columns and lines, and to determine the degree of their interaction in the context of determining the effectiveness of the experiment. The data obtained during the focus group survey were processed using the Textalyser (n./d.) web wool. To process students' answers to the questions, we identified the most commonly used positive words in the answers that helped us identify broad categories of answers such as: "improvement", "health", "motivation", "speed", "concentration", "future work". We then split the answers by the frequency of the words listed above. Answers that did not fall into the category were analyzed manually.

Also, the methods of studying the motivation of professional activity (Your psychologist, n./d.; Dobre, 2013), the technique of revealing the value orientations of Murzina's (2014) personality "Square of values", the orientation questionnaire "Orientation of personality" by Bass were used (Psychology of Happy Life, 2008); methods of studying the formation of design competence, modified diagnostic techniques Semichenko (2004) "Motives of study in higher education", methods "Self-assessment of emotional state" Wasmann and Ricks (Kokun et al., 2011); methodology and scale for determining the adaptive potential (Baiev, 2014), the method of determining biological age and computer rapid health diagnostics by "Biopulsar-Reflexograph" to determine the developmental status of value-motivational and activity-reflexive components of activity and monitoring of the psychophysical state of the student in physical education.

A technique of studying the motivation of professional activity (Your psychologist, n./d.; Dobre, 2013), Murzina's (2014) technique for identifying the value orientations of personality "Square of Values", an orientation questionnaire "Personality Orientation" by Bass (Psychology of Happy Life, 2008); a technique of studying the level of formation of a design competence, modified diagnostic techniques of Semichenko (2004) "Motives for Studying in a Higher Educational Institution", the methods "Self-Assessment of Emotional State" by Wasmann and Ricks (Kokun et al., 2011); the method and scale for determining the adaptation potential (Baiev, 2014), the method for determining biological age and computer rapid health diagnostics by BiopulsarReflexograph; identification of the state of development of value-motivational 
and activity-reflexive components of student's activity and monitoring of student's psychophysical state in physical education.

\section{Results}

The experiment was conducted under natural conditions of the educational process. And the proposed model contributed to the formation of healthimprovement competencies in future police officers. The table below (Table 2) provides examples of standard deviations and student values from the t-test before and after the experiment in both groups.

Table 2: Indicators of deviations and values of students from the t-test before and after the experiment in the EG and CG

\begin{tabular}{|l|l|l|l|l|}
\hline \multirow{2}{*}{ Groups } & \multicolumn{2}{|c|}{ Before the experiment } & \multicolumn{2}{c|}{ After the experiment } \\
\cline { 2 - 5 } & $M$ & $S D$ & $M$ & $S D$ \\
\hline Experimental & 58.33 & 18.883 & 54.12 & 16.13 \\
\hline Control & 56.38 & 18.369 & 57.31 & 12.84 \\
\hline
\end{tabular}

Note. $M$ - arithmetic mean; $S D$ - standard deviations

It is noteworthy that although the test values (mean scores) before and after the experiment for the experimental group decreased (from 58.33 to 54.12), the values (mean scores) for the control group increased (from 56.38 to 57.31).

Table 3 answers the question whether changes in students' values are statistically significant differences and whether they depend on the model used to teach them.

Table 3: Results of the analysis of the dependence of training results on physical education of future police officers on the model used for their training based on the use of two-way ANOVA

\begin{tabular}{|c|c|c|c|c|c|c|c|}
\hline Variance Source & SS & $d f$ & MS & $\begin{array}{c}F- \\
\text { value }\end{array}$ & $p$ & $\eta^{2}$ & $N$ \\
\hline Between groups & 23201.26 & 83 & & & & & \\
\hline Group (Experimental/control) & 32.44 & 1 & 33.32 & .082 & .771 & 0.001 & 53 \\
\hline Error & 22859.47 & 56 & 422.49 & & & & \\
\hline Inside groups & 10841.72 & 84 & & & & & \\
\hline $\begin{array}{l}\text { Estimated parameters /Before- } \\
\text { /After-the experiment) }\end{array}$ & 1.24 & 1 & 11.18 & .058 & 797 & 0.002 & 53 \\
\hline Group*Parameter & 187.31 & 1 & 168.32 & 887 & .342 & 0.015 & \\
\hline Error & 104789.02 & 57 & 186.155 & & & & \\
\hline Total & 20693.06 & 117 & & & & & \\
\hline
\end{tabular}

Note. ANOVA - analysis of variance; $S S$ - total mean square error; $d f$ - degrees of freedom; MS - mean square; F-value; $\eta^{2}$ - mutual coupling factor; $p>.05 ; n$ - number of students.

This analysis allowed us to establish a statistically significant difference, which expresses the dependence of the results of physical education of future police officers on the model used for their training. 
In order to find out the relationship between the traditional educational environment in terms of physical education and our proposed improvement of students' activity in terms of physical education, descriptive statistics were studied regarding variable research parameters (thinking style aimed at forming health-improvement competences, learning motivation and conscious learning) and correlation between them (see results in Table 4).

Table 4: Descriptive statistics and relationships of variables

\begin{tabular}{|l|l|l|l|}
\hline \multicolumn{1}{|c|}{ Variables } & \multicolumn{1}{|c|}{1} & \multicolumn{1}{c|}{$\mathbf{2}$} & \multicolumn{1}{c|}{3} \\
\hline $\begin{array}{l}\text { 1. Style of thinking aimed at developing } \\
\text { health-improvement competencies }\end{array}$ & 1.00 & & \\
\hline 2. Learning motivation & $.41^{* *}$ & 1.00 & \\
\hline 3. Conscious learning & $.69^{* *}$ & $.43^{* *}$ & 1.00 \\
\hline Mean (Likert scale) & $74.13(4.11)$ & $140.03(5.00)$ & $17.37(3.47)$ \\
\hline Standard deviations & 11.70 & 24.29 & 3.97 \\
\hline
\end{tabular}

${ }^{*} p>.05 .{ }^{* *} p<.01$.

Table 4 illustrates the positive and significant correlation between the values of Style of thinking aimed at developing health-improvement competencies, Learning motivation and Conscious learning. It was found that there is a positive relationship between Style of thinking aimed at developing healthimprovement competencies and Conscious learning $(\mathrm{r}=.41, \mathrm{p}>.05)$; there is also a positive significant relationship between the Style of thinking aimed at developing health-improvement competencies and Conscious learning $(\mathrm{r}=.69$, $\mathrm{p}>.05)$; and there is a positive relationship between Learning motivation and Conscious learning $(\mathrm{r}=.43, \mathrm{p}>.05)$. Thus, all correlation values are positive, which means that the technique we use contributes to the formation of healthimprovement competencies in future police officers by means of a personalityoriented approach to physical education.

3.1. Results of processing of answers of the students of focus group

1) What proportion of time per week did you devote to participating in projectrelated activities? Participants were asked how much time they spent completing project-related tasks per week. 2 out of 11 answered that they were spending two hours a day for the project, 2 students were spending three to four hours, and other students were spending four to five hours.

2) How much time per week did you spend to implement the theoretical part of the project? Answering this question, 9 people stated that they spent 15 to 40 minutes during the day (usually in the first half). 3 people out of 11 spent 1-1.5 hours every day. 1 person confessed that he had no longer devoted time to this part of the project after day 16 .

3) What exactly did you do in this project? When the students were asked what exactly they did in the project, they first mentioned the development of their own training programs (4 of 11 people), self-training (11 people), watching training videos (10 students); 9 out of 11 respondents mentioned the motivating effectiveness of the messages. 
4) What benefits can you personally get from participating in this project? Answering this question, students reported that they can apply the acquired skills and knowledge and that they are important for their profession (11 students), improve their health condition (11 people), selfdevelop (10 people), improve their academic achievements (8 students), increase their self-esteem and motivation (10 students).

5) What problems did you face while participating in the project? Answering this question, 2 out of 11 students indicated that they sometimes experienced problems with motivation, 9 students faced problems related to learning mode, and 1 person accused herself of constant procrastination.

6) What do you propose to do to solve the problems you faced? Regarding the students' suggestions for problem solving, 1 student replied that he would prefer to study according to the traditional model, 4 students offered to extend the duration of the project.

In general, students spoke positively about the format and content of the course. Most of the students of the experimental group reported improvement of their state of mind, speed of thinking, self-organization, results of success, flexibility in problem solving, teamwork skills.

The influence of our developed approach on the state of development of valuemotivational and activity-reflexive components of health-improvement competencies in future police officers by means of personality-oriented approach to physical education is presented in the graph below, measurements were made on a 5-point scale (Figure 3).

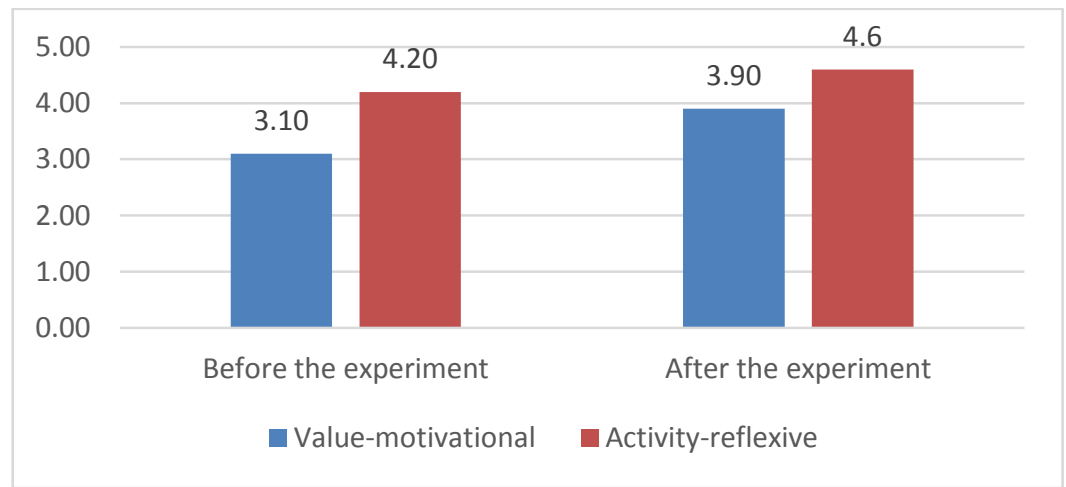

Figure 3: Dynamics of the influence of the developed approach on the state of development of value-motivational and activity-reflexive components of healthimprovement competences in the future police officers by means of personalityoriented approach to physical education, measured on a five-point scale.

It is interesting that $87 \%$ of the focus group students surveyed reported improvements in their academic achievement in other subjects after participating in the experiment.

\subsection{Limitations of the study}

The main limitation for this study is the participation of only one higher educational institution. The other one is the health condition of students in the 
control and experimental groups. The bias of the members of the research team can also be considered as a limitation, as some of them were involved in the development of models, techniques for the development of individual training programs for students and the organization and holding of a 21-day marathon.

\section{Discussion}

It is important to note that such a training model - the 21-Day Health Marathon, with training under their own program of intensive physical self-training under personal guidance of a tutor with a focus on gain-and-loss-framed messages, elements of gamification (badges for certain achievements) - is competenceoriented, and one that is aimed at engaging students in a variety of activities aimed at creating learning intrigue and maintaining student concentration, interest and motivation to learn.

Such model also aims at developing self-improvement skills and health preserving abilities that are currently considered to be crucial and are listed as the key life and career skills of the 21st century (Bellanca \& Brandt, 2010).

As we have also found, the methods used to measure student progress in learning in the context of participating in this type of project do not directly assess the performance of the learning activities that result from it. Therefore, in this study, we attempted to identify tangible (more or less measurable) and intangible (difficult to measure) improvements. In addition to the results of the aforementioned tests or surveys, we took into account the indicators of improvement of scores for summary control check in physical education, the results of general professional training. In our opinion, the students' interest in participating in the project, their confidence in their abilities, responsible attitude and motivation were important indicators.

This study found that implementing an approach that includes the 21-Day Health Marathon, with training under their own program of intensive physical self-training under personal guidance of a tutor with a focus on gain-and-lossframed messages, elements of gamification (badges for certain achievements) in the educational process has the potential to intensify the students' educational activities in the direction of formation of health-improvement competences in future police officers by means of personality-oriented approach to physical training in higher educational institutions of Ukraine of jurisprudential specialization. Forming students' health-improvement competences using this model increases the overall effectiveness of their learning activities as they gain the opportunity to improve their health in their own mode and with a personalized workload, shifting the focus from creating an educational environment in a gym to autonomous activity.

\section{Conclusion and recommendations for future research}

Use of a training model that includes the 21-Day Health Marathon, with training under their own program of intensive physical self-training under personal guidance of a tutor with a focus on gain-and-loss-framed messages, elements of gamification (badges for certain achievements)has a positive effect on the state of development of value-motivational and activity-reflexive components of health- 
improvement competences in future police officers by means of personalityoriented approach to physical education.

In addition, the physical education training model organized according to the algorithm tested in our study allows shifting the formation of healthimprovement competencies of future police officers, which are, a priori, a secondary process in traditional training, to dominant positions where the subjective value of the professionally important subjects increases, and, as a consequence, professional establishment and personal development. Participation in such projects creates the basis for future police officers to become aware of the main direction and model of their future professional activity focused on the formation of personal and professional qualities of a specialist, and not only on obtaining a certain volume of theoretical professional knowledge.

In view of the above, we propose to introduce incentive programs to motivate educational and academic staff of higher education institutions of jurisprudential specialization to develop and implement training models of this type in the practice of physical education of future police officers, which will improve the attitude and form the need for staying in a good shape.

\section{References}

Baiev, O. A. (2014). Study of the Adaptive Potential of the Student Youth. Problems of Environmental and Medical Genetics and Clinical Immunology, 1, 283-289.

Bellanca, J., \& Brandt, R. (2010). 21st Century Skills: Rethinking How Students Learn. Bloomington, IN: Solution Tree.

Boucher, B., Robertson, E., Wainner, R., \& Sanders, B. (2013). "Flipping" Texas State University's physical therapist musculoskeletal curriculum: Implementation of a hybrid learning model. Journal of Physical Therapy Education, 27(3), 72-77.

Dawes, J., Orr, R. M., \& Cocke, C. (2016). The use of two conditioning programs and the fitness characteristics of police academy cadets. Journal of Athletic Training, 51, 887-896.

DeNysschen, C. A., Cardina, C., Sobol, J. J., Zimmerman, B., \& Gavronsky, A. (2018). Health, wellness, and fitness training: A pilot study on preparing physically fit and police academy-ready graduates. International Journal of Police Science $\mathcal{E}$ Management, 20(1), 66-79. https://doi.org/10.1177/1461355718756412

Dicheva, D., Dichev, C., Agre, G., \& Angelova, G. (2015). Gamification in Education: A Systematic Mapping Study. Educational Technology \& Society, 18(3), 1-14.

Dimitrijevic, R., Koropanovski, N., Dopsaj, M., Vuckovic, G., \& Jankovic, R. (2014). The influence of different physical education programs on police students' physical abilities. Policing: An International Journal of Police Strategies \& Management, 37(4), 794-808. https:// doi.org/10.1108/PIJPSM-05-2014-0060

Dobre, O.-I. (2013). Employee motivation and organizational performance. Review of Applied Socio-Economic Research, 5(1), 49-53.

Findlay-Thompson, S., \& Mombourquette, P. (2014). Evaluation of a flipped classroom in an undergraduate business course. Business Education \& Accreditation, 6(1), 63-71.

Greenberg, M. (2015). It's Not a Game: The Dark Side of Gamification. Retrieved from https://newtonew.com/discussions/gamification-dark-side

Kokun, O. M., Pishko, I. O., Lozinska, N. S., Kopanytsia, O. V., \& Malkhazov, O. R. (2011). Collection of Methods for Diagnostics of Psychological Readiness of Servicemen 
under Contract for Activities in the Peacekeeping Units: guidance manual. Kyiv, Ukraine: SIC of the GP Armed Forces.

Lagestad, P., \& Van den Tillaar, R. (2014). A comparison of training and physical performance of police students at the start and the end of three-year police education. Journal of Strength \& Conditioning Research, 28(5), 1394-1400. https://doi.org/10.1519/JSC.0000000000000273

Mahony, D., \& Prenzler, T. (1996). Police study, the university and the police service. An Australian study. Journal of Criminal Justice Education, 7(2), 283-304.

Marczewski, A. (2013). What's the difference between Gamification and Serious Games? Retrieved from http://www.gamasutra.com/blogs/AndrzejMarczewski/20130311/188218/W hats_the_difference_between_Gamification_and_Serious_Games.php

Murzina, O. A. (2014). Formation of Professional Value Orientations in Future Law Enforcement Officers: guidelines. Zaporizhzhia, Ukraine: ZSMU.

Nabeel, I., Baker, B. A., McGrail, M. P., \& Flottermesch, T. J. (2007). Correlation between physical activity, fitness, and musculoskeletal injuries in police officers. Minnesota Medicine, 90(9), 40-43.

O'Donovan, S., Gain, J., \& Marais, P. (2013). A Case Study in the Gamification of a University-level Games Development Course. South African Institute for Computer Scientists and Information Technologists Conference (pp. 245-251). East London, South Africa. https://doi.org/10.1145/2513456.2513469

Plotnikoff, R. C., Costigan, S. A., Williams, R. L., Hutchesson, M. J., Kennedy, S. G., Robards, S. L., et al. (2015). Effectiveness of interventions targeting physical activity, nutrition and healthy weight for university and college students: a systematic review and meta-analysis. International Journal of Behavioural Nutrition and Physical Activity, 12(1), 45. https://doi.org/10.1186/s12966-015-0203-7.

Psychology of Happy Life. (2008). Methods of Diagnostics of Personality Orientation B. Bass (Smekalo-Kucher Questionnaire). Retrieved from https://psycabi.net/testy/233methodics-diagnostics-direction-lichnosti-b-bassa-prosnik-smekala-kuchera

Rothman, A., Bartels, R., Wlaschin, J., \& Salovey, P. (2006). The Strategic Use of Gainand Loss- Framed Messages to Promote Healthy Behavior: How Theory Can Inform Practice. Journal of Communication, 56, 202-220. https:// doi.org/10.1111/j.1460-2466.2006.00290.x.

Semichenko, V. A. (2004). Problems of Motivation of Human Behaviour and Activity. Modular Course in Psychology. Kyiv, Ukraine: Millennium.

Simons-Morton, B. G., McLeroy, K. R., \& Wendel, M. L. (2011). Behavior Theory in Health Promotion Practice and Research. Boston, MA: Jones \& Bartlett Learning.

Textalyser. (n/d). Retrieved from http://textalyser.net/

Your psychologist. (n./d.). Motivation of Professional Activity (K. Zamfir method in modification of A. Rean). Retrieved from http://www.vashpsixolog.ru/psychodiagnostic-school-psychologist/122-testsguidance/716-motivation-professional-activity-c-zamfir-technique-to-modify-aa-reana 